CLINICAL STUDY

\title{
Clinical, genetic, and immunohistochemical characterization of 70 Ukrainian adult cases with post-Chornobyl papillary thyroid carcinoma
}

\author{
Andrii Dinets ${ }^{1,2,3}$, Mykola Hulchiy ${ }^{3}$, Anastasios Sofiadis ${ }^{1,2}$, Mehran Ghaderi $^{4}$, Anders Höög ${ }^{4,5}$, \\ Catharina Larsson ${ }^{1,2}$ and Jan Zedenius ${ }^{1}$ \\ ${ }^{1}$ Department of Molecular Medicine and Surgery, Karolinska Institutet and ${ }^{2}$ Center for Molecular Medicine, Karolinska University Hospital, CMM, L8:01, \\ SE-17176 Stockholm, Sweden, ${ }^{3}$ Kyiv City Teaching Endocrinological Center, 01034 Kyiv, Ukraine, ${ }^{4}$ Department of Oncology-Pathology, Karolinska \\ Institutet, 17176 Stockholm, Sweden and ${ }^{5}$ Department of Pathology-Cytology, Karolinska University Hospital, 17176 Stockholm, Sweden \\ (Correspondence should be addressed to A Dinets at Department of Molecular Medicine and Surgery, Karolinska Institutet; Email: andrii.dinets@ki.se; \\ C Larsson at Department of Molecular Medicine and Surgery, Karolinska Institutet; Email: catharina.larsson@ki.se)
}

\begin{abstract}
Background: Increased incidence of papillary thyroid carcinoma (PTC) is observed as a consequence of radiation exposure in connection to the Chornobyl nuclear plant accident in 1986. In this study, we report a cohort of adult Ukrainian patients diagnosed with PTC from 2004 to 2008 following exposure at the age of 18 years or younger.

Methods: In total, 70 patients were identified and clinically characterized. The common BRAF $1799 \mathrm{~T}>\mathrm{A}$ mutation was assessed by pyrosequencing, the RET/PTC1 and RET/PTC3 (NCOA4) rearrangements by RT-PCR, and the expression of Ki-67 (MIB-1 index), BCL2, cyclin A, and cyclin D1 by immunohistochemistry.

Results: In total, 46/70 (66\%) cases carried a BRAF mutation and/or a RET/PTC rearrangement. A BRAF mutation was detected in 26 tumors, RET/PTC1 in 20 cases, and RET/PTC 3 in four cases. In four of these cases, BRAF mutation and RET/PTC rearrangement were coexisting. The BRAF mutation was underrepresented among PTCs with accompanying chronic lymphocytic thyroiditis (CLT) compared with PTCs without this feature (12 vs 44\%). MIB-1 proliferation index determined by double staining with leukocyte common antigen was low (mean 0.8\%; range 0.05-4.5\%). Moreover, increased expression of cyclin A was observed in PTCs with a tumor size $>2 \mathrm{~cm}$ compared with PTCs $\leq 2 \mathrm{~cm}$ (1.2 vs $0.6 \%)$. BCL2 and cyclin D1 showed frequent expression but without associations to clinical characteristics or amplification of the CCND1 locus.

Conclusions: Our results suggest that this cohort has frequent BRAF mutation, RET/PTC1 rearrangement, and low proliferation index. Furthermore, BRAF 1799T $>A$ was underrepresented in PTCs with CLT, and cyclin A expression was associated with increased PTC tumor size.
\end{abstract}

European Journal of Endocrinology 166 1049-1060

\section{Introduction}

Papillary thyroid carcinoma (PTC) is the most common type of endocrine cancer comprising up to $80 \%$ of all malignant thyroid tumors (1). Increased incidence of PTC was observed among Ukrainian children who were exposed to radioactivity after the Chornobyl (Chernobyl) nuclear plant accident in 1986 (2, 3). Specific molecular and genetic features of such childhood PTC have been described (4). Today, it is known that PTC may also develop in adult individuals who were younger than 18 years at the time of the accident and who lived within the contaminated area $(5,6)$. Molecular changes in such PTC have not been widely studied, and it is presently unclear whether they have similar and/or distinct molecular characteristics compared with PTC in other populations.

PTC commonly exhibits a hotspot BRAF (v-raf murine sarcoma viral oncogene homolog B1) mutation or activation of the RET or NTRK genes through different translocations that lead to abnormal tyrosine kinase activity $(4,7)$. The common BRAF mutation involves a thymine to adenine transversion at position $1799(1799 \mathrm{~T}>\mathrm{A})$ in exon 15 , which results in an activating missense substitution of valine to glutamic acid at codon 600 (V600E) (4). The frequency of BRAF mutation in PTC varies between studies from very low frequencies up to $80 \%(8,9,10)$, and their presence is reported to have prognostic implications (8). However, a low prevalence of BRAF mutation was reported commercial use, distribution, and reproduction in any medium, provided the original work is properly cited. 
for PTCs that developed after the Chornobyl accident $(9,10,11,12)$.

Rearrangements of the RET proto-oncogene are also frequently found in PTC and lead to expression of chimerical transcripts termed RET/PTC due to fusion of the tyrosine kinase domain of RET (TK-RET) with various regions of other genes. RET/PTC1 and RET/PTC 3 are the most common forms of RET/PTC constituting up to $90 \%$ of all RET rearrangements (13). RET/PTC1 is the result of a translocation between the coiled-coil domain-containing 6 gene (CCDC6) and TKRET, while fusion of the NCOA4 with TK-RET leads to the formation of RET/PTC3. The frequency of reported RET/PTC rearrangements varies largely between studies $(7,12,13,14,15)$. High frequencies of RET/PTC3 have been reported in post-Chornobyl childhood PTC, in contrast to adult PTC in which RET/PTC1 is more common $(13,14,15)$.

PTCs are also characterized by expression of certain immunohistochemical markers such as Ki-67, BCL2, cyclin A, and cyclin D1 involved in proliferation and apoptosis. BCL2 is involved in blocking of apoptosis (16) and cell survival (17), and BCL2 overexpression correlates with PTC aggressiveness (18). Ki-67 is a nuclear protein expressed in proliferating cells, and the MIB-1 MAB against Ki-67 is used for determination of the proliferation index (MIB-1 index). In PTC, increased MIB-1 index has been associated with a worse prognosis in some studies but not in others $(19,20,21,22)$. Cyclin A activates cyclin-dependent kinases to regulate proliferation and cell cycle progression through the S phase to the G2-M checkpoint (23). Cyclin A expression has possible prognostic value in breast cancer (24); however, its role in PTC has been less studied $(25,26)$. Cyclin D1 is involved in cell cycle control at the G1 checkpoint for progression from G1 to $S$ phase. Expression of cyclin D1 is not observed by immunohistochemistry in normal thyroid cells, while its overexpression has been associated with higher frequency of lymph node metastases $(27,28)$.

We have identified a cohort of 70 adult patients with PTC who were exposed in their childhood or as teenagers to the Chornobyl radioactive fallout in 1986. Here, we describe the cohort concerning clinical features, expression, and mutation data for some established and some putative prognostic markers: BRAF, RET/PTC1, RET/PTC3, MIB-1 index, BCL2, cyclin A, and cyclin D1.

\section{Materials and methods}

\section{Patients and tissue samples}

The 70 cases included in the study were identified from patients surgically treated for a PTC from 2004 to 2008 in Kyiv City Teaching Endocrinological Center, Ukraine. The standard surgical approach used for these patients was total thyroidectomy followed by central lymph node dissection. All patients in the cohort had been exposed to radioactivity from the accident at the Chornobyl nuclear power station in Ukraine in 1986, as determined from the patients' addresses and the geographical pattern of the radioactive fallout. However, data about radiation dosages are not available. At the time of the accident, all patients were 18 years of age or younger and lived near the most heavily contaminated regions Kyiv, Chernihiv, or Zhitomyr (6).

Clinical data were retrieved from medical records, and archival formalin-fixed paraffin-embedded (FFPE) tumor tissue samples were collected for all cases. The tumors were initially classified as primary PTC, classical type, at routine histopathological examination in Kyiv City Teaching Endocrinological Center, whereby presence or absence of coexisting chronic lymphocytic thyroiditis (CLT) was also noted. The diagnosis, presence/absence of CLT, as well as the absence of large lymphocytic infiltrates of the PTC stroma were subsequently confirmed at histopathological revision by one of the authors (A H). In addition, specimens of normal thyroid tissue $(n=4)$, goiter $(n=1)$, and follicular thyroid adenoma $(n=1)$ were collected at the same institution and included as references in the immunohistochemistry and fluorescence in situ hybridization (FISH) analysis. Samples were collected, and the study was conducted with ethical permission obtained from the local ethics committees.

Control samples for pyrosequencing constituted 11 PTC samples with BRAF T1799A mutation status confirmed by Sanger sequencing as previously reported for ten of the cases by Sofiadis et al. (29), as well as three parathyroid adenomas. These samples had been collected as fresh frozen samples at the Karolinska University Hospital, Sweden, with informed consent and ethical approval.

\section{Pyrosequencing of the BRAF 1799T $>$ A mutation}

Genomic DNA (gDNA) was extracted from FFPE sections using a commercially available kit (Qiagen), quantified with a Nano Drop 1000 Spectrophotometer (Thermo Fisher Scientific Inc., Wilmington, DE, USA) and used for pyrosequencing. Primers for PCR amplification of BRAF exon 15 and subsequent pyrosequencing were designed using the Pyromark Q24 Software 2.0 (Qiagen) and commercially synthesized (biomers.net GmbH, Ulm, Germany). The primer sequences were as follows: forward 5'-GGCCAAAAATTTAATCAGTGGAA- ${ }^{\prime}$, reverse 5'-CTTCATAATGCTTGCTCTGATAGG-3' (5'-biotinylated) and sequencing $5^{\prime}$-CCACTCCATCGAGATT- $3^{\prime}$. PCRs were performed using HotStar Taq DNA polymerase kit (Qiagen) under the following cycling conditions: $95^{\circ} \mathrm{C}$ for $15 \mathrm{~min}, 35$ cycles $\times\left(94^{\circ} \mathrm{C}\right.$ for $30 \mathrm{~s}, 58^{\circ} \mathrm{C}$ for $30 \mathrm{~s}$, and $72{ }^{\circ} \mathrm{C}$ for $30 \mathrm{~s}$ ) and final extension at $72{ }^{\circ} \mathrm{C}$ for $10 \mathrm{~min}$. PCR products were 
visualized in 2\% agarose gel stained with GelRed (Biotium, Hayward, CA, USA). Subsequently, $30 \mu \mathrm{l}$ biotinylated PCR product was captured to filtered probes using PyroMark Q24 vacuum prep workstation, flushed, and released to Q24 plates with annealing solution according to the protocol recommended by the manufacturer. Plates with annealed samples were processed in a Pyromark Q24 and the results were analyzed using Pyromark Q24 Software 2.0 (Qiagen). Pyrosequencing of additional DNA samples from PTC cases with a BRAF $1799 \mathrm{~T}>\mathrm{A}$ mutation or wild-type status previously determined by standard Sanger sequencing was done as positive and negative controls respectively (29). The accuracy of the pyrosequencing was evaluated by analysis of 11 PTCs for which the $B R A F$ 1799T $>$ A mutation determined by Sanger sequencing was verified. Furthermore, the sensitivity was demonstrated by detection of the mutation in gDNA diluted one, five, and ten times from one BRAF 1799T $>$ A mutation carrying PTC. The specificity of the method was determined by detection of the wild-type $B R A F$ sequence only in the three parathyroid adenomas. The cutoff level for BRAF $1799 \mathrm{~T}>\mathrm{A}$ was $10 \%$.

\section{Real-time PCR detection of RET/PTC1 and RET/PTC3 fusion transcripts}

Total RNA was isolated from all samples using RNA isolation kit for FFPE tissue (Qiagen), according to the protocol recommended by the manufacturer. cDNA was synthesized from $100 \mathrm{ng}$ total RNA using highcapacity cDNA RT kit with random primers (Applied Biosystems) according to the manufacturer's description. Amplification of cDNA was performed by RT-PCR in a StepOnePlus PCR instrument using TaqMan Universal PCR master mix (Applied Biosystems). Primers and probes for RET/PTC1 and RET/PTC 3 were synthesized according to Rhoden et al. (30). The phosphoglycerate kinase 1 gene (PGK1) served as endogenous control. Two PTC samples with previously reported expression of RET/PTC1 or RET/PTC3, respectively (14), were included as positive controls, and replacement of cDNA template with water constituted the nontemplate control. RT-PCRs, including negative and positive controls, were performed in duplicate under standard conditions: $50{ }^{\circ} \mathrm{C}$ for $2 \mathrm{~min}$ followed by $95^{\circ} \mathrm{C}$ for $10 \mathrm{~min}$ and 45 cycles $\times\left(95^{\circ} \mathrm{C}\right.$ for $15 \mathrm{~s}$, $60{ }^{\circ} \mathrm{C}$ for $\left.1 \mathrm{~min}\right)$. Analysis of RT-PCR results was based on the evaluation of amplification curves for each sample in comparison with positive controls (31).

\section{Immunohistochemistry}

MIB-1 index and expression of BCL2, cyclin A, and cyclin D1 were analyzed on macroarray tissue slides of the 70 PTCs as well as control thyroid samples by immunohistochemistry using a previously described protocol (29). The following primary antibodies were used for antigen detection: monoclonal mouse anti-Ki67 (clone MIB-1; Dako, Stockholm, Sweden) at dilution 1:300; monoclonal mouse anti-CD45 (leukocyte common antigen, LCA) at 1:50 (clone 2B11+PD7/26; Dako); monoclonal mouse anti-BCL2 (clone 124; Dako) at 1:100; monoclonal rabbit anti-cyclin D1 (clone Sp4; Dako) at 1:250; and monoclonal mouse anti-cyclin A at 1:300 (clone E6E; Novocastra, Leica Biosystems, Newcastle, UK). Macroarrays were prepared by joining and re-embedding of four to nine tissue samples in novel FFPE blocks. For immunohistochemistry, $5 \mu \mathrm{m}$ paraffin sections were deparaffinized, rehydrated, and treated in preheated citrate buffer $\mathrm{pH} 6.0$ (Dako) at $95-99{ }^{\circ} \mathrm{C}$ for $20 \mathrm{~min}$ in a microwave oven. After incubation in $0.3 \%$ hydrogen peroxide for $30 \mathrm{~min}$ and blocking in 1\% BSA with $0.01 \%$ sodium azide for $1 \mathrm{~h}$ at room temperature, endogenous biotin was blocked using the Avidin/Biotin Blocking Kit (SP-2001; Vector Laboratories, Burlingame, CA, USA). Primary antibody diluted in 1\% BSA was incubated overnight at $4{ }^{\circ} \mathrm{C}$ followed by the biotinylated secondary antibody horse antimouse IgG at 1:700 (BA-1000/BA-2000, Vector Laboratories) for $45 \mathrm{~min}$. Slides were subsequently incubated with the avidin-biotin-peroxidase complex (Vectastain Elite Kit; Vector Laboratories) for $45 \mathrm{~min}$ and diaminobenzidine tetrahydrochloride for $6 \mathrm{~min}$ and counterstained with hematoxylin for $3 \mathrm{~min}$. Slides analyzed in parallel with omission of the primary antibody served as negative controls and showed expected absence of staining in all cases. Positive controls constituted of tissue sections from anonymous normal tissues of stomach, large and small bowels, as well as lymphoid tissue, which revealed expected staining patterns in accordance with information provided by the antibody manufacturers. Anticyclin A, anti-cyclin D, and anti-BCL2 were separately incubated. MIB-1 was incubated separately as well as coincubated with anti-LCA to allow optimal differentiation between proliferating leukocytes and proliferating tumor cells.

\section{Evaluation of immunohistochemistry}

Slides were evaluated in a Zeiss Axioskop microscope (Carl Zeiss, Jena, Germany) equipped with Zeiss PlanNeofluar objective lenses, and images were captured using a ProgRes C12 Plus camera and the ProgRes Capture Pro 2.5 software program (Jenoptik, Jena, Germany). For each case, the total number of PTC cells was estimated ( $\times 16$ objective magnification), and the scoring was based on 1500-2000 cells. Non-PTC cells were identified at microscopy and excluded from the scoring of PTC cells. MIB-1 proliferation index and cyclin A expression were determined by counting all positive PTC cells in the areas where the number of immunoreactive nuclei was the highest (hotspot) and by calculating the proportion of positive nuclei. For cyclin D1, only nuclear staining was considered and the proportion of positive PTC cells estimated at 
microscopical evaluation. Cytoplasmic staining pattern was observed for BCL2 and the proportion of positive PTC cells was estimated at microscopical evaluation.

\section{Fluorescence in situ hybridization}

Dual color FISH analysis was performed to evaluate possible regional amplification of the cyclin D1 locus (CCND1) on FFPE sections from the 70 PTC cases. A FISH probe kit (Abbott, Scandinavia) containing a Spectrum Orange-labeled CCND1 probe (11q13) and a Spectrum Green-labeled CEP11 probe for the D11Z1 alpha centromere satellite repeat was used (11p11.11q11). FISH was carried out using the Histology FISH Accessory Kit (Dako) according to the recommendations of the manufacturer. Visualization and scoring of FISH signals were performed in a Zeiss Axioplan 2 imaging epifluorescence microscope (Carl Zeiss) using an $\times 60$ objective. For each case, a minimum of 200 interphase nuclei were scored, including only representative PTC cells with nonoverlapping nuclei and two bright green CEP11 signals. The rationale for this selection was to avoid misscoring of overlapping or sectioned nuclei (32). Sections of an anonymous breast carcinoma with validated CCND1 amplification were analyzed in parallel as positive controls.

\section{Statistical analyses}

Statistical calculations were performed using the data analysis software Statistica version 10.0 (StatSoft Scandinavia AB, Uppsala, Sweden). The Mann-Whitney $U$ test was applied to compare the results in sample groups. Spearman rank order correlation test was performed to analyze possible relations between studied parameters. Results with $P$ values $<0.05$ were regarded as statistically significant.

\section{Results}

\section{Clinical description of the post-Chornobyl PTC cohort}

The cohort consists of 70 patients who were exposed to radioactivity from the Chornobyl accident in 1986 as children or teenagers $(\leq 18$ years) and who were subsequently operated on for a primary PTC from 2004 to 2008. Clinical characterization of patients and tumors was based on medical records and histopathological revision of PTC slides as summarized in Table 1. The mean age of patients was 10.4 years at the time of the Chornobyl accident and 30.4 years at the time of surgery. Female patients were overrepresented 6.8 times compared with male patients (87 vs 13\%). For 52 patients, the size of PTC was $\leq 2 \mathrm{~cm}$ in maximum diameter, whereas 18 patients had a PTC $>2 \mathrm{~cm}$. Metastases to local lymph nodes were detected at the time of diagnosis in 19 cases (27\%). However,
Table 1 Clinical characteristics for the 70 post-Chornobyl PTC patients.

\begin{tabular}{|c|c|}
\hline Parameter & Observation \\
\hline Informative cases $(n)$ & 70 \\
\hline \multicolumn{2}{|l|}{ Gender } \\
\hline Male & 9 \\
\hline Female & 61 \\
\hline Ratio (female:male) & $7: 1$ \\
\hline \multicolumn{2}{|l|}{ Age at diagnosis (years) } \\
\hline Mean & 30.4 \\
\hline Median (range) & $31(19-39)$ \\
\hline \multicolumn{2}{|l|}{ Age at Chornobyl (years) } \\
\hline Mean & 10.4 \\
\hline Median (range) & $12(<1-18)$ \\
\hline \multicolumn{2}{|l|}{ Tumor size $(\mathrm{cm})$} \\
\hline Mean & 1.9 \\
\hline Median (range) & $1.7(1-6)$ \\
\hline \multicolumn{2}{|l|}{ Local lymph node metastasis } \\
\hline No. of cases & $19(27 \%)$ \\
\hline \multicolumn{2}{|l|}{ Distant metastasis } \\
\hline No. of cases & $0(0 \%)$ \\
\hline \multicolumn{2}{|l|}{$\begin{array}{l}\text { Chronic lymphocytic thyroiditis } \\
\text { (CLT) }\end{array}$} \\
\hline No. of cases with PTC/CLT & $16(23 \%)$ \\
\hline No. of cases with PTC only & $54(77 \%)$ \\
\hline
\end{tabular}

distant metastases were not observed. In 16 of the 70 PTC tumors, coexisting CLT was observed (referred to as PTC/CLT), whereas 54 cases did not show this feature (PTC only). Cases with PTC only and PTC/CLT did not differ significantly concerning gender, age at exposure and surgery, tumor size, or metastasis. Similarly, no statistically significant difference was observed when tumor size was compared with gender, age, metastasis, or presence of CLT.

\section{Frequent occurrence of the common BRAF mutation and/or RET/PTC rearrangements}

All 70 cases were screened for the common BRAF mutation in exon 15 using pyrosequencing (Fig. 1). In total, 26 (37\%) tumors exhibited a base substitution $1799 \mathrm{~T}>\mathrm{A}$ predicted to result in the V600E missense mutation (Table 2). Comparison of BRAF mutation status with clinical characteristics did not reveal any significant associations for the parameters gender, sex, age, or lymph node metastasis. However, 24 of the 26 $B R A F$ mutated cases had been classified as PTC only while two cases were of PTC/CLT type. Hence, BRAF mutations were 3.5 times less frequent in the PTC/CLT group $(2 / 16 ; 12 \%)$ compared with PTC only $(24 / 54$; $44 \%)(P=0.02)$. The cutoff level of $10 \%$ was applied to classify cases as positive or negative. Overall, positive cases exhibited proportions of mutant allele, which varied between 12 and 44\%. The proportion of mutant alleles was not found to be different between PTC-only cases (mean 28\%, range 12-44\%) and the two PTC/CLT cases (18 and 34\%).

The presence of a RET/PTC1 or RET/PTC 3 rearrangement was assessed by analysis of amplification curves 
A

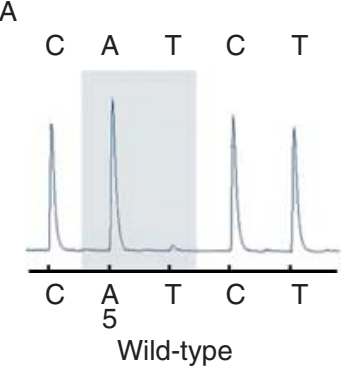

B

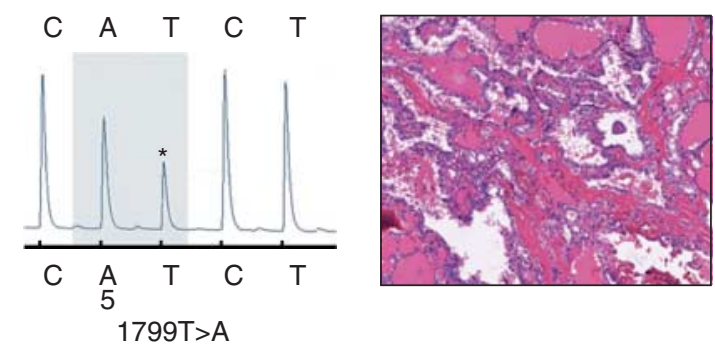

Figure 1 Analysis of the common mutation 1799T $>A$ in exon 15 of $B R A F$ by pyrosequencing. (A) Wild-type $B R A F$ sequence in a case of PTC/CLT, revealed as a large $A$ peak without a subsequent abnormal T peak in the shaded area of the pyrogram. (B) Detection of a 1799T > A mutation in a case of PTC only, revealed as a decreased peak $A$ combined with an elevated peak $T$ (marked by asterisk). ( $C$ and D) Photomicrographs of hematoxylin-stained slides show histopathological findings in (C) a case of PTC/CLT and (D) a PTC only without CLT.

after RT-PCR (Fig. 2). A total of 24 (34\%) tumors showed rearrangement of RET in which RET/PTC1 was validated in 20 cases and RET/PTC 3 in four cases (Table 2). Hence, these rearrangements were commonly observed in the cohort and RET/PTC1 was five times more frequent than RET/PTC3. Associations between RET/PTC1 or RET/PTC3 and clinical parameters were not observed.

A genetic alteration commonly associated with PTC, i.e. a BRAF $1799 \mathrm{~T}>\mathrm{A}$ mutation or a RET/PTC rearrangement, was detected in 46 of the 70 PTCs. These included 22 cases with the BRAF 1799T $>$ A mutation only, 17 with a RET/PTC1 rearrangement only, three with RET/PTC3 only, three with BRAF 1799T $>$ A and RET/PTC1, and one case with BRAF 1799T $>A$ and RET/PTC3. In 24 tumors, neither BRAF 1799T $>A$ nor a RET/PTC rearrangement was revealed.

\section{MIB-1 proliferation index}

Proliferation index was determined using MIB-1 immunohistochemistry and counting of cells with positive nuclei (Fig. 3 and Table 2). Lymphocytes used as internal controls showed strong nuclear staining in more than $50 \%$ of the cells. Given the frequent occurrence of lymphocytes in the PTC specimens, including 16 cases with PTC/CLT, we performed double staining with LCA to facilitate the distinction between proliferative lymphocytes and tumor cells (Fig. 3). All 70 PTC cases were positive, while normal thyroid tissues included in the FFPE macroarrays of the PTC cohort were completely negative (Table 3). The mean MIB-1 index for the entire cohort determined by combined MIB-1/LCA immunohistochemistry was $0.8 \%$ (range 0.05-4.5\%). For comparison, MIB-1 index was also determined by regular counting of MIB-1-stained slides, applying visual distinction between proliferating lymphocytes and proliferating tumor cells. This analysis showed that 65/70 PTCs were positive with a mean MIB- 1 index of $1.5 \%$ (median $1.0 \%$, range $0-7.5 \%$ ). Comparison of MIB-1 index with clinical characteristics did not reveal statistically significant associations for the MIB-1/LCA- or MIB-1based analyses.

\section{Expression of cyclin $A$ in relation to size of PTC}

Cyclin A expression was determined by scoring of immunohistochemical nuclear expression (Fig. 4A and B). In normal thyroid tissue, no staining was observed (Table 3). In the PTC cohort, the mean level of

Table 2 Summary of genetic and immunohistochemical findings in the 70 cases of post-Chornobyl PTCs studied. Cutoff level for positive cases was $0 \%$ for all antibodies.

\begin{tabular}{lc}
\hline Parameter studied & $\begin{array}{c}\text { Observation } \\
\text { in } 70 \text { PTCs }\end{array}$ \\
\hline BRAF 1799T>A mutation & \\
No. with 1799T>A & $26(37 \%)$ \\
No. with wild-type & $44(63 \%)$ \\
RET/PTC1 rearrangement & \\
No. with RET/PTC1 & $20(29 \%)$ \\
No. without rearrangement & $50(71 \%)$ \\
RET/PTC3 rearrangement & \\
No. with RET/PTC3 & $4(6 \%)$ \\
No. without rearrangement & $66(94 \%)$ \\
BRAF and RET/PTC & \\
No. with 1799T>A and RET/PTC1 & $3(4 \%)$ \\
No. with 1799T A and RET/PTC3 & $1(1 \%)$ \\
No. with BRAF wild-type and no RET/PTC & $22(31 \%)$ \\
MIB-1 proliferation index (MIB-1 only) & \\
Mean proportion positive nuclei & $1.5 \%$ \\
Median proportion positive nuclei & $1.0 \%$ \\
MIB-1 proliferation index (MIB-1+anti-LCA) & \\
Mean proportion positive nuclei & $0.8 \%$ \\
Median proportion positive nuclei & $0.7 \%$ \\
No. of positive cases & $70(100 \%)$ \\
Cyclin A immunohistochemistry & \\
Mean proportion positive cells & $0.7 \%$ \\
Median proportion positive cells & $0.4 \%$ \\
No. of positive cases & $64(92 \%)$ \\
Cyclin D1 immunohistochemistry & \\
Mean proportion positive nuclei & $27 \%$ \\
Median proportion positive nuclei & $20 \%$ \\
No. of positive cases & \\
BCL2 immunohistochemistry & \\
Mean proportion positive cells & \\
Median proportion positive cells & \\
No. of positive cases & $48 \%$ \\
\hline & $53(76 \%)$ \\
\hline
\end{tabular}




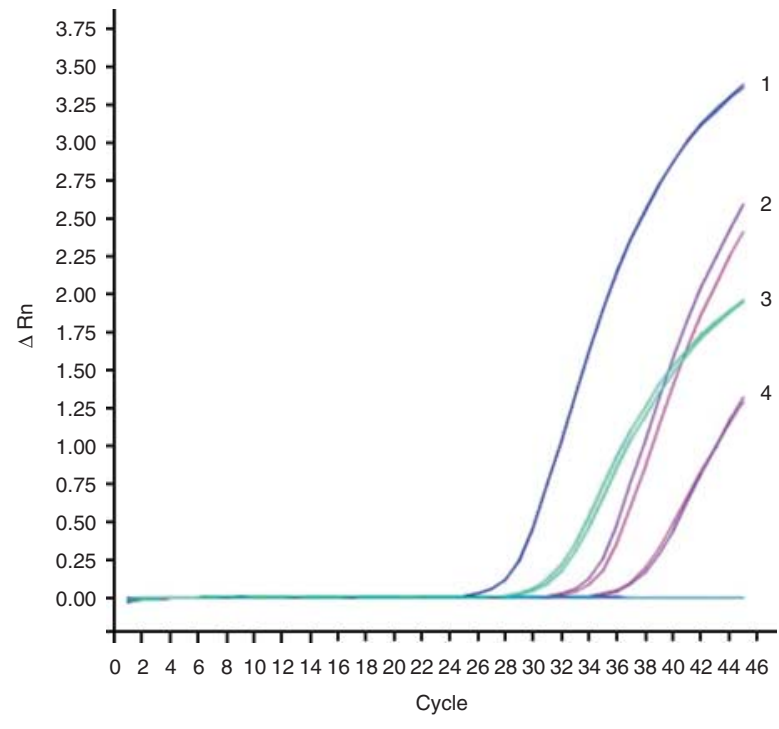

Figure 2 Detection of a RET/PTC1 fusion by reverse-transcribed PCR. The amplification curves 1 and 3 reveal the presence of RET/PTC1 in a PTC case (curve 1), and the positive control with previously validated RET/PTC1 (curve 3). Curves 2 and 4 correspond to amplification of the endogenous control PGK1.

expression was $0.7 \%$ positive cells ranging from 0 to $3.9 \%$. Six PTC cases were negative with lack of immunoreactive PTC cells. Among the 64 tumors with cyclin A expression, 48 cases showed $<1 \%$ positive cells and 16 exhibited $1-4 \%$ positive cells according to the previously published recommendations of classification (33). When compared with the clinical characteristics, we found that the expression of cyclin A differed significantly according to the size of the PTC. Specifically, expression of cyclin A was higher in PTCs $>2 \mathrm{~cm}$ than in PTCs $\leq 2 \mathrm{~cm}(P=0.004$; mean 1.2 vs $0.6 \%$ respectively). No other association between cyclin A expression and clinical parameters was noted.

\section{Frequent expression of cyclin D1 without associated CCND1 amplification}

Cyclin D1 was evaluated concerning both protein expression and regional amplification of the CCND1 locus. Cyclin D1 immunohistochemistry was negative in normal thyroid tissue (Table 3). In the PTC cohort, we detected nuclear immunoexpression of cyclin D1 (Fig. 4C and D), and in addition, cytoplasmic staining was also noted in some cases, which was not included in the scorings. The mean proportion of positive PTC cells was $27 \%$ ranging from 0 to $90 \%$. Sixty-eight cases showed expression with $<10 \%$ positive cells in 25 cases, $10-49 \%$ positive cells in 25 cases, and $\geq 50 \%$ positive cells in the remaining 18 cases according to the previously applied cutoff levels for subgroups (34). No association was detected between the expression level and clinical characteristics. FISH analysis in normal thyroid tissue showed two signals for the CCND1 probe.
Moreover, FISH analyses revealed two bright green and two bright orange signals in all representative PTC cells for all cases. This observation suggests that the observed cyclin D1 expression was not a consequence of CCND1 regional amplification.

\section{Expression of BCL2}

Immunohistochemical expression of BCL2 was identified in the majority of PTC cases and observed in normal thyroid tissue and goiter (Table 3 and Fig. 4E and F). Among the 70 PTC cases, the mean level of expression was $48 \%$ ranging from 0 to $100 \%$ positively stained cells. Altogether, 53 cases exhibited BCL2 expression, in $1-25 \%$ of the cells for 13 cases, in $26-50 \%$ of cells for eight cases, and in $>50 \%$ of cells in 32 cases. The remaining 17 cases were negative without immunoreactive PTC cells. Normal thyroid tissue and goiter were strongly positive with $>75 \%$ positively stained cells in $4 / 5$ samples (Table 3 ). No association with clinical parameters was identified.
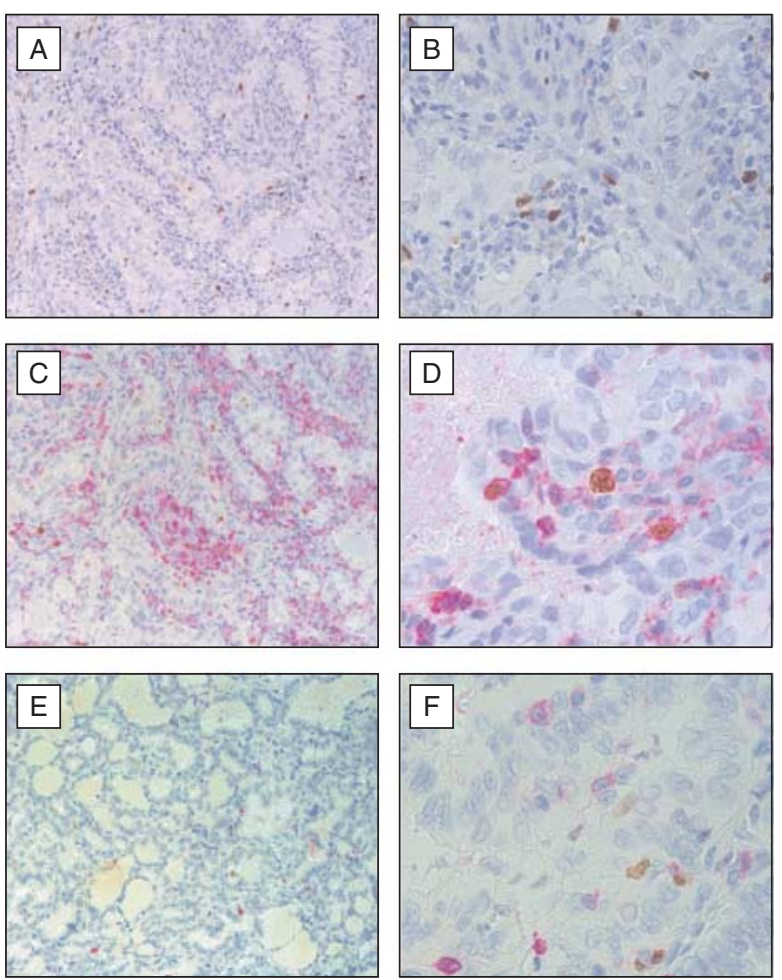

Figure 3 Analysis of MIB-1 proliferation index by immunohistochemistry using MIB-1 only or double staining with MIB-1 and anti-LCA. (A and B) A case of PTC/CLT shown after regular MIB-1 staining with immunoreactivity in PTC cells and proliferating lymphocytes. (C and D) The same case after double staining with MIB-1 and anti-LCA showing proliferative PTC cells (brown), proliferative lymphocytes (red and brown), and nonproliferative lymphocytes (red). (E and F) A case of PTC only without CLT after MIB-1 and anti-LCA double staining. Slides are shown in different magnifications using $(A, C$ and $E)$ objective $\times 16$; $(B) \times 40$; or $(\mathrm{D}$ and $\mathrm{F}) \times 63$. 
Table 3 Expression of MIB-1, BCL2, cyclin A, and cyclin D1 in nonmalignant tissues. Cutoff level for positive cases was $0 \%$ for all antibodies.

\begin{tabular}{lcccc}
\hline Parameter & MIB-1 & BCL2 & Cyclin A & Cyclin D1 \\
\hline $\begin{array}{l}\text { Normal thyroid }(n=4) \\
\quad \text { Negative }\end{array}$ & 4 & 0 & 4 & 4 \\
$\quad \begin{array}{l}\text { Positive } \\
\text { Follicular thyroid }\end{array}$ & 0 & 4 & 0 & 0 \\
$\quad$ adenoma $(n=1)$ & & & & \\
$\quad \begin{array}{l}\text { Negative } \\
\quad \text { Positive }\end{array}$ & 0 & 0 & 0 & 0 \\
Goiter $(n=1)$ & 1 & 1 & 1 & 1 \\
$\quad$ Negative & 1 & 0 & 1 & 1 \\
Positive & 0 & 1 & 0 & 0 \\
\hline
\end{tabular}

\section{Comparison between genetic and immunohistochemical phenotypes}

Possible relationships between the genetic findings and immunohistochemical parameters assessed in the study were determined by Spearman's rank order correlation test. Several statistically significant observations were made. MIB-1 index showed a positive correlation with expression levels of both cyclin A $(r=0.38, P<0.05)$ and cyclin D1 $(r=0.34, P<0.05)$. Cyclin D1 expression levels showed a positive correlation with cyclin A expression $(r=0.39, P<0.05)$ and a negative correlation with the presence of RET/PTC1 $(r=-0.26, P<0.05)$. Finally, a positive correlation was found between BRAF mutation and BCL2 expression $(r=0.24, P<0.05)$. However, for all identified correlations, Cohen's effect size was $<0.5$, suggesting that the detected correlations are relatively weak.

\section{Discussion}

In this study, we present a comparably large cohort of patients operated on for PTC, who were exposed to radioactive fallout in their childhood or as teenagers after the Chornobyl nuclear plant accident in 1986. The clinical features do not appear to be significantly different compared with other cohorts of PTC patients who were not exposed to radioactivity. Whether this cohort has a significantly different clinical course awaits follow-up; however, the time allowing for prognostic evaluation is presently too short. One weakness of the study is the lack of a control group in the experiments, in order to shed light over the specificity of the findings. A control group, however, would require recruitment from a totally different age group, or from another, noncontaminated, geographic area with a different demographic profile. Therefore, we decided not to include a control group in the experiments but to compare all the findings with existing data on similar cohorts found in the literature.

To further characterize the cohort, we have applied some established markers often used in the work-up of PTC patients. Some of these markers are summarized in Table 4, containing details of observations from published studies of postradiation PTCs and nonradiation-associated PTCs. The frequency of BRAF mutation in the entire cohort was $37 \%$, which is similar to many series of nonradiation PTC $(35,36)$. By contrast, BRAF mutation has been less frequently observed in postradiation PTC, i.e. 4-24\% (Table 4). It is worth noticing that BRAF mutation was significantly underrepresented among the patients with PTC/CLT compared with PTC only, which is in accordance with the previous studies $(37,38)$. The finding may also reflect the facts that BRAF mutation has been associated with more aggressive PTC $(39,40)$ while the presence of CLT in PTC seems to lead to a better prognosis $(41,42)$. Thus, the fewer occurrences of BRAF mutation in PTC/CLT patients may also be connected to good prognosis.

In this study, we determined the proportion of BRAF mutant alleles to be below 50\% (mean 28\%), which could be related to contamination of nontumor cells in the samples studied as well as intratumoral heterogeneity of the BRAF mutation. The latter situation was recently shown by Guerra et al. (43). In our study, histopathological examination of all samples indicated a high PTC representativity with minor proportions of non-PTC cells. This was also true for the PTC/CLT cases in which large areas of lymphocytic infiltrations were not observed. Taken together with the sensitivity of the
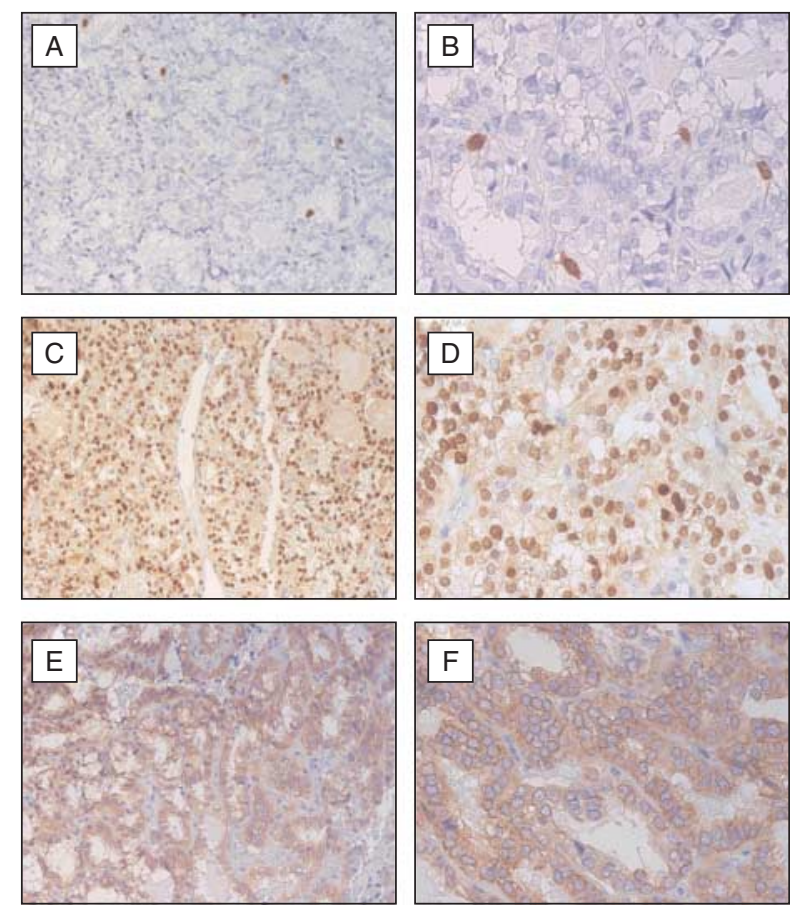

Figure 4 Immunohistochemical analysis of cyclin A, cyclin D1, and $B C L 2$ expression shown in small (objective $\times 16$, left) or large magnification (objective $\times 40$, right). (A and $B$ ) Cyclin $A$ expression of $2.8 \%$ in a large-sized PTC $>2 \mathrm{~cm}$; (C and D) cyclin D1 expression of $70 \%$ in a sample of PTC only; and (E and F) BCL2 expression of $90 \%$ in a PTC-only sample. 


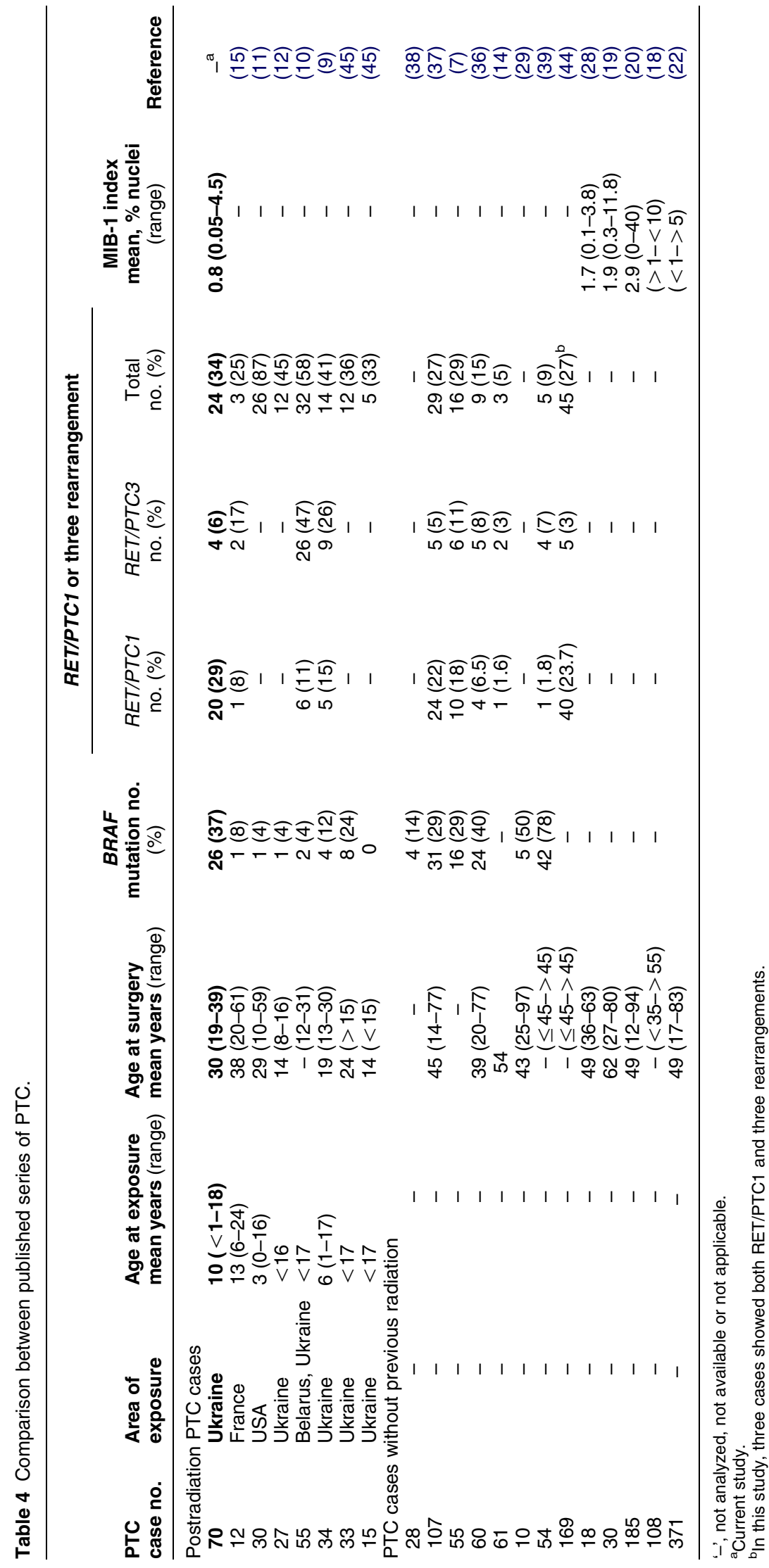


pyrosequencing (by which BRAF 1799T $>$ A was observed in gDNA of a PTC after dilution), our observations would support intratumoral heterogeneity for $B R A F 1799 \mathrm{~T}>\mathrm{A}$.

RET/PTC rearrangements in the form of RET/PTC1 and RET/PTC3 were demonstrated in 29 and $6 \%$ respectively. While previous studies on RET/PTC have reported highly varying frequencies from 5 to $87 \%$ (Table 4), postradiation cases have generally shown the highest frequencies. In comparison with these reports, our finding of $34 \%$ RET/PTC positivity falls within the lower range of postradiation PTC and is comparable to the highest frequencies among nonradiation PTCs $(15,37,44)$. However, with regard to the specific fusion type involved, we found RET/PTC1 to be five times more common than RET/PTC3, which is in contrast to other reported postradiation PTCs but in agreement with nonradiation PTCs (45). Overall, the presence of $R E T / P T C$ is usually considered to be a sign of poor prognosis in PTC. Moreover, RET/PTC accompanied by a BRAF $1799 \mathrm{~T}>\mathrm{A}$ mutation is associated with a high risk of disease recurrence and metastases. In the current study, co-occurrence of RET/PTC and $B R A F$ mutation was detected in four PTCs. Although the clinical features at surgery were not indicative of poor prognosis, these cases should be considered for close follow-up for early recognition of signs for PTC recurrence as reported in the literature $(13,39)$.

Moreover, different frequencies of RET/PTC1 and RET/PTC3 were reported in childhood post-Chornobyl PTC. However, these studies showed significant variation of these genetic aberrations depending on the histopathological type of PTC. Thus, RET/PTC1 was associated with the classical and diffuse sclerosing variants of PTC, whereas RET/PTC 3 was associated with the solid follicular type $(46,47)$. On the other hand, the solid follicular type of PTC is more common in pediatric patients, while the classical PTC is more common in adults (47). The patient's age is also an important factor for the BRAF 1799T $>A$ mutation, which is commonly found in adult patients, but is rare in childhood PTC, which is consistent with our finding (9, 10).

MIB-1 index is increasingly used in the immunohistochemical work-up of several cancer types. The MIB-1 MAB is directed toward the nuclear antigen Ki-67 and is used for identification of proliferative cells and areas of tumors with a high degree of proliferation. This index has been suggested to predict the prognosis in many cancer varieties, including PTC $(19,20,21)$. PTC exhibits varying proportions of infiltrating lymphocytes, which was pronounced in the PTC/CLT entity and was less abundant in several PTC-only cases. As MIB-1 immunostaining targets proliferating cells, both proliferating lymphocytes and tumor cells will be stained, with associated risks of misclassification and false-positive or negative scoring as a consequence. To achieve optimal scoring conditions, we used double staining with MIB-1 and LCA in addition to regular MIB-1 staining of all cases. Typical examples of the result are illustrated in Fig. 3. Overall, lower MIB-1 proliferation index was revealed using the MIB-1/LCAbased analysis compared with MIB-1 only (mean 0.8 vs $1.5 \%$; Table 2). If substantiated in follow-up studies, the observations suggest that double staining of MIB-1 and LCA should be considered for use in clinical routine work-up of PTC instead of regular MIB-1-only analysis. Associations between MIB-1 proliferative index and clinical features were not observed. In the five cases with MIB-1 index above the $\geq 1.85 \%$ border applied in our previous studies $(19,20)$, signs of aggressive clinical features were not observed concerning histopathological and clinical features present at the time of surgery. However, in some previous publications, increased MIB-1 index in PTC has been associated with adverse outcome during follow-up $(19,20,22)$. Possible prognostic implications of MIB-1 index in this cohort cannot be presently assessed given the lack of follow-up.

Expression of the antiapoptotic protein BCL2 was observed in the majority of PTCs. All normal thyroid tissue samples and 53/70 PTCs expressed BCL2, suggesting that BCL2 could have a protective role to prevent apoptosis in normal thyroid, which is partly lost in malignancy. In contrast to a previous study, no correlation was observed between BCL2 expression and MIB-1 index in PTC/CLT cases (48). However, a positive correlation was observed between BCL2 expression and $B R A F$ mutation. Although this correlation was not strong, it is consistent with the study by Preto et al. (49), showing inhibition of BCL2 in PTC cell lines treated with the BRAF and kinase inhibitor sorafenib. Moreover, the lack of association between clinical features and BCL2 expression in our cohort is consistent with the observations by Siironen et al. (18). Given that phosphorylation is needed for the antiapoptotic effect of BCL2 (50), further determination of phosphorylated BCL2 expression levels would add more information about the antiapoptotic status of PTC.

We observed significantly elevated expression of cyclin A in PTCs larger than $2 \mathrm{~cm}$. Previous studies of this protein have reported overexpression in poorly differentiated and undifferentiated thyroid cancers, indicating a role in thyroid carcinoma de-differentiation (25). Our finding of an association between cyclin A expression and tumor size implies that cyclin A could have prognostic value in irradiation-associated PTC; however, much longer follow-up is required to prove or disprove this. Although the possible utility of cyclin A for routine clinical practice is presently unclear, the observed association warrants further investigation of cyclin A in relation to follow-up.

Cyclin D1 expression was detected in the majority of PTCs. This was not accompanied by regional amplification of the CCND1 locus, suggesting that cyclin D1 is deregulated at the transcriptional, translational, or posttranslational level. In our scorings, 
we have included nuclear expression of cyclin D1 as suggested elsewhere (34). However, we have also observed cytoplasmic staining, which could be explained by cytoplasmic sequestration of cyclin D1 due to inhibition of its transportation to the nucleus $(51,52)$. Elevated expression of cyclin D1 was found to be correlated with elevated MIB-1 index, an association that was also demonstrated by Alama et al. (53) in meningioma. No other associations to clinical or pathological features were observed, which is in agreement with the previous studies $(34,54)$. However, others have reported that cyclin D1 overexpression may be a prognostic marker for PTC $(55,56)$.

In summary, we report a cohort of adult PTC patients exposed to the radioactive fallout from the Chornobyl accident during their childhood or as teenagers. Our results from genetic and molecular characterization suggest that this cohort is characterized by frequent BRAF $1799 \mathrm{~T}>\mathrm{A}$ mutation and RET/PTC1 rearrangement as well as low proliferation, which are partly overlapping and partly distinguishing from other reported cohorts of postradiation- and nonradiationrelated PTC. Moreover, BRAF mutation was significantly underrepresented in the PTC/CLT group, and cyclin A expression was associated with tumor size in this entity. Long-term follow-up in this cohort will eventually identify possible effects on patient outcome in this patient group.

\section{Declaration of interest}

The authors declare that there is no conflict of interest that could be perceived as prejudicing the impartiality of the research reported.

\section{Funding}

This work was supported by the Swedish Cancer Society, the Swedish Research Council, the Cancer Society in Stockholm, the Stockholm County Council, and Karolinska Institutet. A Dinets is a recipient of a KIRT scholarship in the Visby Program of the Swedish Institute.

\section{Acknowledgements}

The authors wish to thank Dr Iryna Avetisian and Lisa Ånfalk for excellent assistance with retrieval and handling of tissue samples; Dr Mohsen Karimi for expert advice regarding pyrosequencing; and Monica Jansson for consultation concerning FISH.

\section{References}

1 Sipos JA \& Mazzaferri EL. Thyroid cancer epidemiology and prognostic variables. Clinical Oncology 201022 395-404. (doi:10.1016/j.clon.2010.05.004)

2 Tronko MD, Howe GR, Bogdanova TI, Bouville AC, Epstein OV, Brill AB, Likhtarev IA, Fink DJ, Markov VV, Greenebaum E, Olijnyk VA, Masnyk IJ, Shpak VM, McConnell RJ, Tereshchenko VP, Robbins J, Zvinchuk OV, Zablotska LB, Hatch M, Luckyanov NK, Ron E, Thomas TL, Voilleque PG \& Beebe GW. A cohort study of thyroid cancer and other thyroid diseases after the chornobyl accident: thyroid cancer in Ukraine detected during first screening. Journal of the National Cancer Institute 200698 897-903. (doi:10. 1093/jnci/djj244)

3 Avetisian IL, Gulchiy NV, Demidiuk AP \& Stashuk AV. Thyroid pathology in residents of the Kiev region, Ukraine, during preand post-Chernobyl periods. Journal of Environmental Pathology, Toxicology and Oncology 199615 233-237.

4 Trovisco V, Soares P, Preto A, Castro P, Maximo V \& SobrinhoSimoes M. Molecular genetics of papillary thyroid carcinoma: great expectations. Arquivos Brasileiros de Endocrinologia $e$ Metabologia 200751 643-653. (doi:10.1590/S0004-27302007 000500002)

5 Likhtarov I, Kovgan L, Vavilov S, Chepurny M, Ron E, Lubin J, Bouville A, Tronko N, Bogdanova T, Gulak L, Zablotska L \& Howe G. Post-Chernobyl thyroid cancers in Ukraine. Report 2: risk analysis. Radiation Research 2006166 375-386. (doi:10.1667/ RR3593.1)

6 Jacob P, Bogdanova TI, Buglova E, Chepurniy M, Demidchik Y, Gavrilin Y, Kenigsberg J, Kruk J, Schotola C, Shinkarev S, Tronko MD \& Vavilov S. Thyroid cancer among Ukrainians and Belarusians who were children or adolescents at the time of the Chernobyl accident. Journal of Radiological Protection 200626 51-67. (doi:10.1088/0952-4746/26/1/003)

7 Frattini M, Ferrario C, Bressan P, Balestra D, De Cecco L, Mondellini P, Bongarzone I, Collini P, Gariboldi M, Pilotti S, Pierotti MA \& Greco A. Alternative mutations of BRAF, RET and NTRK1 are associated with similar but distinct gene expression patterns in papillary thyroid cancer. Oncogene 2004 23 7436-7440. (doi:10.1038/sj.onc.1207980)

8 Kebebew E, Weng J, Bauer J, Ranvier G, Clark OH, Duh QY, Shibru D, Bastian B \& Griffin A. The prevalence and prognostic value of BRAF mutation in thyroid cancer. Annals of Surgery 2007 246 466-470 (discussion 470-461). (doi:10.1097/SLA. Ob013e318148563d)

9 Lima J, Trovisco V, Soares P, Maximo V, Magalhaes J, Salvatore G, Santoro M, Bogdanova T, Tronko M, Abrosimov A, Jeremiah S, Thomas G, Williams D \& Sobrinho-Simoes M. BRAF mutations are not a major event in post-Chernobyl childhood thyroid carcinomas. Journal of Clinical Endocrinology and Metabolism 200489 4267-4271. (doi:10.1210/jc.2003-032224)

10 Nikiforova MN, Ciampi R, Salvatore G, Santoro M, Gandhi M, Knauf JA, Thomas GA, Jeremiah S, Bogdanova TI, Tronko MD, Fagin JA \& Nikiforov YE. Low prevalence of BRAF mutations in radiation-induced thyroid tumors in contrast to sporadic papillary carcinomas. Cancer Letters 2004209 1-6. (doi:10.1016/j.canlet. 2003.12.004)

11 Collins BJ, Schneider AB, Prinz RA \& Xu X. Low frequency of BRAF mutations in adult patients with papillary thyroid cancers following childhood radiation exposure. Thyroid 200616 61-66. (doi:10.1089/thy.2006.16.61)

12 Powell N, Jeremiah S, Morishita M, Dudley E, Bethel J, Bogdanova T, Tronko M \& Thomas G. Frequency of BRAF T1796A mutation in papillary thyroid carcinoma relates to age of patient at diagnosis and not to radiation exposure. Journal of Pathology 2005205 558-564. (doi:10.1002/path.1736)

13 Santoro M, Melillo RM \& Fusco A. RET/PTC activation in papillary thyroid carcinoma: European Journal of Endocrinology Prize Lecture. European Journal of Endocrinology 2006155 645-653. (doi:10.1530/eje.1.02289)

14 Kjellman P, Learoyd DL, Messina M, Weber G, Hoog A, Wallin G, Larsson C, Robinson BG \& Zedenius J. Expression of the RET protooncogene in papillary thyroid carcinoma and its correlation with clinical outcome. British Journal of Surgery 200188 557-563. (doi:10.1046/j.1365-2168.2001.01734.x)

15 Ory C, Ugolin N, Levalois C, Lacroix L, Caillou B, Bidart JM, Schlumberger M, Diallo I, de Vathaire F, Hofman P, Santini J, Malfoy B \& Chevillard S. Gene expression signature discriminates sporadic from post-radiotherapy-induced thyroid tumors. Endocrine-Related Cancer 201118 193-206. (doi:10.1677/ERC10-0205) 
16 Cleland MM, Norris KL, Karbowski M, Wang C, Suen DF, Jiao S, George NM, Luo X, Li Z \& Youle RJ. Bcl-2 family interaction with the mitochondrial morphogenesis machinery. Cell Death and Differentiation 201118 235-247. (doi:10.1038/cdd.2010.89)

17 Mitsiades CS, Hayden P, Kotoula V, McMillin DW, McMullan C, Negri J, Delmore JE, Poulaki V \& Mitsiades N. Bcl-2 overexpression in thyroid carcinoma cells increases sensitivity to Bcl-2 homology 3 domain inhibition. Journal of Clinical Endocrinology and Metabolism 200792 4845-4852. (doi:10.1210/jc.2007-0942)

18 Siironen P, Nordling S, Louhimo J, Haapiainen R \& Haglund C. Immunohistochemical expression of Bcl-2, Ki-67, and p21 in patients with papillary thyroid cancer. Tumour Biology 200526 50-56. (doi:10.1159/000084340)

19 Kjellman P, Wallin G, Hoog A, Auer G, Larsson C \& Zedenius J. MIB-1 index in thyroid tumors: a predictor of the clinical course in papillary thyroid carcinoma. Thyroid 200313 371-380. (doi:10.1089/105072503321669866)

20 Sofiadis A, Tani E, Foukakis T, Kjellman P, Skoog L, Hoog A, Wallin G, Zedenius J \& Larsson C. Diagnostic and prognostic potential of MIB-1 proliferation index in thyroid fine needle aspiration biopsy. International Journal of Oncology 200935 369-374. (doi:10.3892/ijo_00000348)

21 Viacava P, Bocci G, Tonacchera M, Fanelli G, DeServi M, Agretti P, Berti E, Goletti O, Aretini P, Resta ML, Bevilacqua G \& Naccarato AG. Markers of cell proliferation, apoptosis, and angiogenesis in thyroid adenomas: a comparative immunohistochemical and genetic investigation of functioning and nonfunctioning nodules. Thyroid 200717 191-197. (doi:10.1089/thy.2006.0175)

22 Ito Y, Miyauchi A, Kakudo K, Hirokawa M, Kobayashi K \& Miya A. Prognostic significance of ki-67 labeling index in papillary thyroid carcinoma. World Journal of Surgery $2010 \mathbf{3 4} 3015-3021$. (doi:10.1007/s00268-010-0746-3)

23 Chibazakura T, Kamachi K, Ohara M, Tane S, Yoshikawa H \& Roberts JM. Cyclin A promotes S-phase entry via interaction with the replication licensing factor Mcm7. Molecular and Cellular Biology 201131 248-255. (doi:10.1128/MCB.00630-10)

24 Ahlin C, Aaltonen K, Amini RM, Nevanlinna H, Fjallskog ML \& Blomqvist C. Ki67 and cyclin A as prognostic factors in early breast cancer. What are the optimal cut-off values? Histopathology 200751 491-498. (doi:10.1111/j.1365-2559.2007.02798.x)

25 Ito Y, Yoshida H, Nakano K, Takamura Y, Kobayashi K, Yokozawa T, Matsuzuka F, Matsuura N, Kuma K \& Miyauchi A. Expression of G2-M modulators in thyroid neoplasms: correlation of cyclin A, B1 and cdc2 with differentiation. Pathology, Research and Practice 2002198 397-402. (doi:10.1078/0344-033800272)

26 Nar A, Ozen O, Tutuncu NB \& Demirhan B. Cyclin A and cyclin B1 overexpression in differentiated thyroid carcinoma. Medical Oncology 201129 294-300. (doi:10.1007/s12032-010-9800-0)

27 Troncone G, Volante M, Iaccarino A, Zeppa P, Cozzolino I, Malapelle U, Palmieri EA, Conzo G, Papotti M \& Palombini L. Cyclin D1 and D3 overexpression predicts malignant behavior in thyroid fine-needle aspirates suspicious for Hurthle cell neoplasms. Cancer Cytopathology 2009117 522-529. (doi:10.1002/cncy.20050)

28 Lantsov D, Meirmanov S, Nakashima M, Kondo H, Saenko V, Naruke Y, Namba H, Ito M, Abrosimov A, Lushnikov E, Sekine I \& Yamashita S. Cyclin D1 overexpression in thyroid papillary microcarcinoma: its association with tumour size and aberrant beta-catenin expression. Histopathology $2005 \quad 47 \quad 248-256$. (doi:10.1111/j.1365-2559.2005.02218.x)

29 Sofiadis A, Dinets A, Orre LM, Branca RM, Juhlin CC, Foukakis T, Wallin G, Hoog A, Hulchiy M, Zedenius J, Larsson C \& Lehtio J. Proteomic study of thyroid tumors reveals frequent up-regulation of the $\mathrm{Ca}^{2+}$-binding protein $\mathrm{S} 100 \mathrm{~A} 6$ in papillary thyroid carcinoma. Thyroid 201020 1067-1076. (doi:10.1089/thy. 2009.0400)

30 Rhoden KJ, Johnson C, Brandao G, Howe JG, Smith BR \& Tallini G. Real-time quantitative RT-PCR identifies distinct c-RET, RET/ PTC1 and RET/PTC3 expression patterns in papillary thyroid carcinoma. Laboratory Investigation $2004 \mathbf{8 4}$ 1557-1570. (doi:10.1038/labinvest.3700198)
31 Cyniak-Magierska A, Wojciechowska-Durczynska K, KrawczykRusiecka K, Zygmunt A \& Lewinski A. Assessment of RET/PTC1 and RET/PTC3 rearrangements in fine-needle aspiration biopsy specimens collected from patients with Hashimoto's thyroiditis. Thyroid Research 20114 5. (doi:10.1186/1756-6614-4-5)

32 Katz RL, Caraway NP, Gu J, Jiang F, Pasco-Miller LA, Glassman AB, Luthra R, Hayes KJ, Romaguera JE, Cabanillas FF \& Medeiros LJ. Detection of chromosome 11q13 breakpoints by interphase fluorescence in situ hybridization. A useful ancillary method for the diagnosis of mantle cell lymphoma. American Journal of Clinical Pathology 2000114 248-257. (doi:10.1309/69EJ-RFM5-E976BUTP)

33 Achille M, Boukheris H, Caillou B, Talbot M, de Vathaire F, Sabatier L, Desmaze C, Schlumberger M \& Soria JC. Expression of cell cycle biomarkers and telomere length in papillary thyroid carcinoma: a comparative study between radiation-associated and spontaneous cancers. American Journal of Clinical Oncology 2009 32 1-8. (doi:10.1097/COC.0b013e3181783336)

34 Lee SH, Lee JK, Jin SM, Lee KC, Sohn JH, Chae SW \& Kim DH. Expression of cell-cycle regulators (cyclin D1, cyclin E, p27kip1, p57kip2) in papillary thyroid carcinoma. Otolaryngology - Head and Neck Surgery 2010142 332-337. (doi:10.1016/j.otohns. 2009.10.050)

35 Yip L, Nikiforova MN, Carty SE, Yim JH, Stang MT, Tublin MJ, Lebeau SO, Hodak SP, Ogilvie JB \& Nikiforov YE. Optimizing surgical treatment of papillary thyroid carcinoma associated with BRAF mutation. Surgery 2009146 1215-1223. (doi:10.1016/j. surg.2009.09.011)

36 Puxeddu E, Moretti S, Elisei R, Romei C, Pascucci R, Martinelli M, Marino C, Avenia N, Rossi ED, Fadda G, Cavaliere A, Ribacchi R, Falorni A, Pontecorvi A, Pacini F, Pinchera A \& Santeusanio F. BRAF(V599E) mutation is the leading genetic event in adult sporadic papillary thyroid carcinomas. Journal of Clinical Endocrinology and Metabolism 200489 2414-2420. (doi:10.1210/jc. 2003-031425)

37 Muzza M, Degl'Innocenti D, Colombo C, Perrino M, Ravasi E, Rossi S, Cirello V, Beck-Peccoz P, Borrello MG \& Fugazzola L. The tight relationship between papillary thyroid cancer, autoimmunity and inflammation: clinical and molecular studies. Clinical Endocrinology 201072 702-708. (doi:10.1111/j.1365-2265. 2009.03699.x)

38 Sargent R, LiVolsi V, Murphy J, Mantha G \& Hunt JL. BRAF mutation is unusual in chronic lymphocytic thyroiditis-associated papillary thyroid carcinomas and absent in non-neoplastic nuclear atypia of thyroiditis. Endocrine Pathology 200617 235-241. (doi:10.1385/EP:17:3:235)

39 Henderson YC, Shellenberger TD, Williams MD, El-Naggar AK, Fredrick MJ, Cieply KM \& Clayman GL. High rate of BRAF and RET/PTC dual mutations associated with recurrent papillary thyroid carcinoma. Clinical Cancer Research 200915 485-491. (doi:10.1158/1078-0432.CCR-08-0933)

40 O'Neill CJ, Bullock M, Chou A, Sidhu SB, Delbridge LW, Robinson BG, Gill AJ, Learoyd DL, Clifton-Bligh R \& Sywak MS. $\mathrm{BRAF}(\mathrm{V} 600 \mathrm{E})$ mutation is associated with an increased risk of nodal recurrence requiring reoperative surgery in patients with papillary thyroid cancer. Surgery $2010 \mathbf{1 4 8} 1139-1145$ (discussion 1145-1146). (doi:10.1016/j.surg.2010.09.005)

41 Kashima K, Yokoyama S, Noguchi S, Murakami N, Yamashita H, Watanabe S, Uchino S, Toda M, Sasaki A, Daa T \& Nakayama I. Chronic thyroiditis as a favorable prognostic factor in papillary thyroid carcinoma. Thyroid $1998 \mathbf{8}$ 197-202. (doi:10.1089/thy. 1998.8.197)

42 Kim EY, Kim WG, Kim WB, Kim TY, Kim JM, Ryu JS, Hong SJ, Gong G \& Shong YK. Coexistence of chronic lymphocytic thyroiditis is associated with lower recurrence rates in patients with papillary thyroid carcinoma. Clinical Endocrinology 200971 581-586. (doi:10.1111/j.1365-2265.2009.03537.x)

43 Guerra A, Sapio MR, Marotta V, Campanile E, Rossi S, Forno I, Fugazzola L, Budillon A, Moccia T, Fenzi G \& Vitale M. The primary 
occurrence of BRAFV600E is a rare clonal event in papillary thyroid carcinoma. Journal of Clinical Endocrinology and Metabolism 201297 517-524. (doi:10.1210/jc.2011-0618)

44 Nakazawa T, Kondo T, Kobayashi Y, Takamura N, Murata S, Kameyama K, Muramatsu A, Ito K, Kobayashi M \& Katoh R. RET gene rearrangements (RET/PTC1 and RET/PTC3) in papillary thyroid carcinomas from an iodine-rich country (Japan). Cancer 2005104 943-951. (doi:10.1002/cncr.21270)

45 Kumagai A, Namba H, Saenko VA, Ashizawa K, Ohtsuru A, Ito M, Ishikawa N, Sugino K, Ito K, Jeremiah S, Thomas GA, Bogdanova TI, Tronko MD, Nagayasu T, Shibata Y \& Yamashita S. Low frequency of BRAFT1796A mutations in childhood thyroid carcinomas. Journal of Clinical Endocrinology and Metabolism $2004 \quad 89$ 4280-4284. (doi:10.1210/jc.2004-0172)

46 Maenhaut C, Detours V, Dom G, Handkiewicz-Junak D, OczkoWojciechowska M \& Jarzab B. Gene expression profiles for radiation-induced thyroid cancer. Clinical Oncology 201123 282-288. (doi:10.1016/j.clon.2011.01.509)

47 Hess J, Thomas G, Braselmann H, Bauer V, Bogdanova T, Wienberg J, Zitzelsberger H \& Unger K. Gain of chromosome band $7 \mathrm{q} 11$ in papillary thyroid carcinomas of young patients is associated with exposure to low-dose irradiation. PNAS 2011108 9595-9600. (doi:10.1073/pnas.1017137108)

48 Okayasu I, Saegusa M, Fujiwara M, Hara Y \& Rose NR. Enhanced cellular proliferative activity and cell death in chronic thyroiditis and thyroid papillary carcinoma. Journal of Cancer Research and Clinical Oncology 1995121 746-752. (doi:10.1007/BF0121 3321)

49 Preto A, Goncalves J, Rebocho AP, Figueiredo J, Meireles AM, Rocha AS, Vasconcelos HM, Seca H, Seruca R, Soares P \& Sobrinho-Simoes M. Proliferation and survival molecules implicated in the inhibition of BRAF pathway in thyroid cancer cells harbouring different genetic mutations. BMC Cancer 20099387. (doi:10.1186/1471-2407-9-387)
50 Bassik MC, Scorrano L, Oakes SA, Pozzan T \& Korsmeyer SJ. Phosphorylation of BCL-2 regulates ER $\mathrm{Ca}^{2+}$ homeostasis and apoptosis. EMBO Journal 200423 1207-1216. (doi:10.1038/sj. emboj.7600104)

51 Alao JP, Gamble SC, Stavropoulou AV, Pomeranz KM, Lam EW, Coombes RC \& Vigushin DM. The cyclin D1 proto-oncogene is sequestered in the cytoplasm of mammalian cancer cell lines. Molecular Cancer 20065 7. (doi:10.1186/1476-4598-5-7)

52 Sumrejkanchanakij P. Eto K \& Ikeda MA. Cytoplasmic sequestration of cyclin D1 associated with cell cycle withdrawal of neuroblastoma cells. Biochemical and Biophysical Research Communications 2006340 302-308. (doi:10.1016/j.bbrc.2005.11.181)

53 Alama A, Barbieri F, Spaziante R, Bruzzo C, Dadati P, Dorcaratto A \& Ravetti JL. Significance of cyclin D1 expression in meningiomas: a preliminary study. Journal of Clinical Neuroscience $2007 \mathbf{1 4}$ 355-358. (doi:10.1016/j.jocn.2006.04.001)

54 Brzezianska E, Cyniak-Magierska A, Sporny S, PastuszakLewandoska D \& Lewinski A. Assessment of cyclin D1 gene expression as a prognostic factor in benign and malignant thyroid lesions. Neuro Endocrinology Letters 200728 341-350.

55 Melck A, Masoudi H, Griffith OL, Rajput A, Wilkins G, Bugis S, Jones SJ $\&$ Wiseman SM. Cell cycle regulators show diagnostic and prognostic utility for differentiated thyroid cancer. Annals of Surgical Oncology 200714 3403-3411. (doi:10.1245/s10434-007-9572-8)

56 Pesutic-Pisac V, Punda A, Gluncic I, Bedekovic V, Pranic-Kragic A \& Kunac N. Cyclin D1 and p27 expression as prognostic factor in papillary carcinoma of thyroid: association with clinicopathological parameters. Croatian Medical Journal 200849 643-649. (doi:10.3325/cmj.2008.5.643)

Received 21 December 2011

Revised version received 23 March 2012

Accepted 28 March 2012 